مجلة جامعة الملك عبدالعزيز: الآداب والعلوم الانسانية، م23، ص ص: 153-173 (2016م/1436هـ1436ه)

DOI:10.4197 / Art.23-8

\title{
A Content Analysis of Banner Ads in Three Well-known Telecom Companies in Saudi Arabia
}

\author{
Wijdan al-Widyani and Amel Shoaib \\ King Abdulaziz University
}

\begin{abstract}
The present study focuses on a content analysis of online banner advertisements of three well-known telecom company websites : STC, Mobily, and Zain. Although there are hundreds of people in Saudi Arabia (both Saudis and expatriates) who use at least one of these three companies as their mobile/Internet expatriates) who use at least one of these three companies as their mobile/Internet
provider there is scarce research that has investigated this specific type of ad in this particular country for these specific consumers. Therefore, this study is mapping out the terrain for how language works for this form of discourse and identifying its most prominent linguistic features. To achieve this end, 60 online banner ads were used to examine the linguistic means utilized by three telecom companies on their websites. The data were analyzed following Lapšanskás (2006) linguistic classification at various linguistic levels: semar various linguistic levels. semantic, syntactic, lexical morphological, and phonological. The findings sugge that online banner ad langely at various linguistic levels. Moreover, they also depict that all three companies use very simila linguistic features in their banner ads and are not very different from international telecom company ads. Also, the study provides evidence that the products and services that these telecom companies advertise indicate a deep understanding of their consumers. Finally, the findings will provide Saudi-based telecom companies with empirical data that could help their language marketing tactics.
\end{abstract}

Key Words: linguistics, content analysis, advertising, online banner advertisements, Saudi Arabia

\section{Introduction:}

Advertising is a widely used form of marketing communication that has acquired the attention of scholars worldwide. According to The American Heritage Dictionary, it is defined as the action of grasping an audience's attention to a product by paid announcements in newspapers, radio, or electronic media (Advertising, 2014). Within the field of marketing, it is defined as the part of a companies' communication policy, which determines what tools can be used to communicate with an audience (Janoschka, 2004). A further even more 
specific definition, which encompasses all elements of ads, states that advertising, is "The means by which goods or services are promoted to the public" (Petley, 2003, p. 4). All the aforementioned definitions of advertising indicate the importance of the relationship between advertisers and consumers. Thus, the main focus of advertising is the potential consumer and how to win him/her over.

Online advertising has been in use for about two decades by business owners around the globe. Its history goes back to the early beginnings of the World Wide Web. According to Janoschka (2004), it became widely available to the public at the very end of the $20^{\text {th }}$ century. In 1994, the first Online Banner Ad (OBA henceforth) was displayed (Lile, 2009), when the online magazine HotWired displayed an ad on its website for the AT\&T telecom company (Kaye \& Medoff, 2001; as cited in Evans, 2009). For this reason, the coinage of the term "banner ad" was attributed to HotWired (Donaldson, 2008). Nowadays, this marketing trend has become extremely creative with most websites displaying different types of OBAs for different products in request for the sponsorship they receive from the companies they advertise for.

Focusing on online advertising in specific, different formats are now being used worldwide. The annual IAP report for the year 2013 represents the revenue of multiple advertising methods used on the Internet (IAP, 2014). Eight formats in specific are mentioned in the report: search, display (or banner), mobile, digital video, classifieds, lead generation, rich media, and sponsorship. In addition to the latter, other types have also been reported in the literature such as banner plain text, floating, pop-up, music, and embedded video advertisements (Alijani, Mancus, Kwun, \& Omar, 2010). Actually, most websites display one or more of these formats. However, it is banner advertising that this study is focusing on.

\section{OBAs}

Online advertising and particularly OBAs have been around for some time now. It is the original aspect that this format of ads has (mainly the implementation of the click feature) that produces such an impact on consumers (Janoschka, 2004). As Donaldson (2008) indicates, OBAs were first run by Prodigy in 1993, prior to McCarthy's (the founder of e-media in 1993 who designed the banner that was displayed on the HotWired website); yet, it is the latter to whom the invention of the trackable ad is attributed. He preferred the implementation of text on a black background, for his belief in the power that words have in provoking surfers' reaction (Janoschka, 2004).

However, it is worth noting that Internet-based ads have had mixed reactions 
throughout its short history. The positive face of web ads is stated by Rochet and Tirole (2003) and Anderson and Gabszewicz (2005) who feature it as a win-win situation (as cited in Evans, 2009) where both producers and consumers interact with each other simultaneously for the good of both of them. Contrastingly, Evans (2009, p. 37) describes web advertising as a "gale of creative destruction” quoting Schumpeter's (1942) words on advertising and media. That is, the withdrawal of print readership and consequently the shift of advertisers to its electronic counterpart. Another critic of online ads is Janoschka (2004, p. 66) who argues that they are "web ad traps" due to their sudden appearance and ability to take online surfers to another page. In spite of the mixed reactions, OBAs are being used worldwide and by different people for different purposes and is still being researched especially in the Western world.

\section{Advertising Research in the Arab World}

In the literature pertaining to research and Western advertising, it would appear that it has been flourishing throughout history (see Cheng, 2014). However, the same cannot be said for the Middle East or Arab countries. To the knowledge of the researchers, not much has been written about advertising in general or online banner advertising in specific either in English or even Arabic for this particular region of the world. Nonetheless, what is there can be described at both the macro and micro levels. On the macro level, a few Arab researchers have been studying ads but from a different perspective from the present study. Barhouma (2005), for example, discusses the spread of foreign names in commercial billboards in Jordan. Among the Egyptian studies is Al-Sayyed's (2012) which focuses on advertising in the field of banking. In Sudan, Ahmed (2011) writes on the effect of e-marketing on e-banking services. On the micro level, Saudi researchers such as Kutubkhaneh, Baghdadi, Ghanim, Al-jammal, and Andergiri (1993) measure the effect of TV advertisements on Saudi social values. Another study by Al-Qahtani (2008) addresses the reaction of the Saudi society towards TV tourism ads. Finally, a study by Alhuqail (2012) discusses the impact of advertising creativity on purchasing decisions of Saudi women. As is apparent for the latter, research concerning the language of advertising in the Arab world is still in its infancy.

\section{Importance of the Study}

To the knowledge of the researcher, no work has been devoted to study the language of telecom company OBAs in Saudi Arabia although smartphones are an integral part of Saudi/expatriate users' daily lives. Previous research investigating online advertising in the Arab world have looked at this topic in terms of impact, reaction, and effect of advertising on the consumer. With this study, an analysis of the language will be done 
which is something is where the gap is in the literature. Moreover, as this study was sponsored by the Ministry of Labor, the topic of the study was geared towards conducting research that would help society somehow and in our case, it was providing Saudi-based telecom companies with empirical data that could help provide a better understanding of OBA language marketing tactics. Therefore, as there is no research pertaining to such ads in this particular country and at the same time there is a societal need for such a type of investigation, this study is mapping out the terrain for a better understanding of the linguistic make-up of Saudi-specific online advertising which can lead to better telecom marketing 'language' decisions for this particular Middle Eastern country.

\section{Research Question}

This paper is concerned with addressing one important question and that is: what are the discursive strategies utilized by STC, Mobily, and Zain in their OBAs on their websites?

\section{Methodology}

\section{Data Collection}

The data sample for this study consists of sixty Arabic OBAs from the official websites of STC, Mobily, and Zain (the Saudi Arabian Website); three well-known telecom companies in Saudi Arabia. However, only 21 of these ads were included in the Appendices due to spatial constraints (see Appendix 1). The OBAs that were used were the ones used as examples in the Results and Discussion section of the paper. The rest of the ads had similar linguistic features and therefore were not included. The the whole dataset for the study can be obtained upon request from the researchers. These ads appeared between March 3 and April 3, 2014. The data were obtained from both the homepages of these three telecom companies and from the embedded pages within each of the websites. It is worth pointing out that there are many types of online advertisements that these three companies use but it is banner ads that this study is focusing on. These OBAs were advertising the following: packages, services, and apps. It is worth noting that all the data are translated to English (see Appendix 1) and transcribed using the IPA Character Picker 11 (Ishida, 2006).

\section{Theoretical Framework}

For this study, a content analysis approach was chosen. According to Budd, Thorpe, and Donohew (1967, cited in Kassarjian, 1977, p. 9), it "is a systematic technique for analyzing message content and message handling- it is a tool for observing and analyzing the overt communication behavior of selected communicators". Kover (2001) states that content analysis's main objective is to 
investigate what advertising is and it is through this idea that this study was inspired. The intention being to map out the linguistic terrain of Saudi OBAs for a better understanding of online advertising which can lead to better marketing practices by advertising companies in the future.

The reason for choosing content analysis was influenced by two important factors. We were first influenced by * Lapšanská's (2006) idea that linguists are focusing on the language of advertising because they want to explore how certain language works in this specific form of discourse and which linguistic aspects are most prominent to convince potential consumers to buy a product or service. Schrenk (2009) claims that ad language works on the subconscious level of the audience and is designed to have an effect on their purchase decisions. Thus being an affective mean of attracting customers, copywriters make use of the power of language to reach their ultimate goal. Therefore, it is no wonder that it caught the attention of researchers. The practical guidelines for the study were drawn from Lapšanská's (2006) linguistic division which are as follows: semantic, syntactic, lexical, morphological, and phonological, all of which

* Jana Lapšanská’s 2006 study was used to guide the analytical structure of the present study. She analyzed the language of a body of advertising text through the identification of different linguistic features. The researchers for this study followed her linguistic categorization to help ground the present study in a similar area of investigation. will be defined and elaborated on in the Results and Discussion section below.

\section{Grounded Theory and the Coding Process}

The goal of this study was to identify underlying themes based on Lapšanská's (2006) linguistic division: semantic, syntactic, lexical, morphological, and phonological. This required a qualitative methodology of thematic analysis to discover themes and subthemes that would then be sorted to a manageable number (Ryan \& Bernard, 2003). In grounded theory, themes, or categories can be described as the classification of concepts that are compared against one another and ruled to contain a similar phenomenon (Strauss \& Corbin, 1990). Different subcategories were identified from the data and placed under their relevant categories. These sub-categories that emerged were a product of both the data itself and the researchers' understanding of the phenomenon under investigation. In the current study, the data were analyzed using Glaser and Strauss' constant comparative process (1967). This method of systematic comparison between the different ads of each company helped answer the question: What type of linguistic features are present in the OBAs of the three telecom companies? The observed similarities allowed the grouping together of ideas into the following categories and sub-categories: Semantics and its sub-categories (Hyperbole, Visual Metaphor, and Antithesis); Syntax and 
its sub-categories (Sentence type [Imperative and Interrogative] and Sentence Structure [Ellipses and In-complete Sentences]); Morphology and Lexical and their subcategories [utilization of personal pronouns, and rule-breaking techniques]; Phonology and its sub-categories [Rhyme, Rhythm, alliteration, and assonance]. This method of theme analysis was chosen because all of the ads were short, specifically oriented pieces of text rather than long, rich narratives. Thus, it was feasible to move through the dataset multiple times looking for sub-categories between the different OBAs. The process was reiterated until the sub-categories were clearly distinctive from one another. Existing research was used in the later stages of the process to reinforce theme distinction. On a final note, it is worth pointing out that it was not the aim of this study to measure frequencies of linguistic features due to the fact that the OBA numbers were small and also because the aim of the research was to identify the types of linguistic features present in Saudi OBAs to map out the terrain for future researchers in this particular region of the world. In future studies with bigger datasets, this issue would have to be considered.

\section{Transferability and Validity}

Regarding transferability, the researchers followed the 2006 categorical division that
Lapšanská came up with and then went through the data numerous times in order to identify the different sub-categories pertaining to every division. Thus, the study presents both the findings and analysis in a very detailed way. It is because of this, that we believe this study could be easily replicated by others (Merriam, 2003). It is believed that, guided by the original steps of this study, researchers will be able to explore different contexts and anticipate what might reasonably be expected to arise in them.

Moreover, another important element of any research methodology is the issue of validity. Gibbs (2007, cited in Creswell, 2014) emphasizes the importance of checking for validity in the accuracy of any findings. In this study, after the themes were identified, five additional coders reviewed the findings according to their specific major. All questions or disputes were resolved through discussion. They were mostly differences in terminology use. Fortunately for this study, a number of colleagues (syntacticians and a Mass Communication researcher) went through the data analysis concentrating on issues relating to their major and provided valuable feedback that enhanced the quality of the findings. 


\section{Results and Discussion}

\section{OBA Linguistic Features}

As was mentioned above, the study will follow the classification set by Lapšanská (2006). It deals with the four main linguistic categories when investigating text: semantics, syntax, lexical morphology, and phonology. It is worth noting here that all the images used in the discussion are located in Appendix 1 and they are numbered according to their occurrence in the text.

\section{i. The semantic level}

Semantics refers to the study of meaning in language. It is the meaning or the interpretation of a word, sentence, or other language forms. One of the most commonly used aspects in ads under the semantic domain is "hyperbole", by which a sense of exaggeration is established to indicate emphasis. This semantic feature is clear in all ads by STC, Mobily, and Zain (see Appendix 1). Words such as "PəlPərjəћ” (الأريح/most comforting - see Image 1), "Pak日ər" (أكثر/All see Image 2), and "Pol?əwfər" (الأوفر/most economical - see Image 3), are used to give emphasis to products or services that they are attached to. It is worth mentioning that Schrank (1993) argues that it is illegal for advertisers to claim that their product is "better" than another within the same product category because it is understood to be comparative and considered an overt claim of superiority. He adds that it can only be used when comparing a product to something from another category (not a competing brand) or if this product has indeed been proven to be superior over products in its own category. According to Schrank (1993), "best" means "equal to", i.e. if all brands are identical, they must all be of equal goodness (p. 544). So, the previous superlative forms mean that the product equals other competing services in the same field. Another hyperbolic device that is used in the data is the use of 'all' (brkolImage 3/ kolana- Image 4/ kol- Image 5). Such a form of hyperbole has been used to give a sense of exaggeration that some advertisers deliberately like to use sometimes. So, such types of hyperbole forms were used to protect the advertisers from illegal advertising practices especially since it is equality they are trying to depict rather than superiority.

The three telecom companies also make use of "visual metaphor" where texts are accompanied by images to help the consumer easily understand an ad. According to Lakoff and Johnson (1980), metaphor means to use text or pictures to help the audience understand one thing in terms of another (as cited in Lapšanská, 2006). A good example of this is illustrated in Images 6, 7, and 8 (see Appendix 1). In image 6 , the broken PlayStation handle indicates anger resulting from poor data transfer while playing online. A similar problem is exhibited in Image 7; a 
semi-blurred picture on an $\mathrm{iPad} /$ tablet screen resembles what it means to have poor data service. Finally, Image 8 , utilizes a picture of different goods which gives a sense of 'more'; 'an abundance of goods' consumers would get thanks to "nıqa:tt”" (نقاطي/credit). It is important to understand that readers cannot fully comprehend the written part of an ad until they look at the accompanying image to get the whole message (Lapšanská, 2006).

One last semantic feature found in the data is 'personification'. According to Leech, it is a figure of speech in which human properties are attributed to inanimate or abstract things (as cited in Fišer, 2007). Images 8, 9, and 10 exhibit personification uses in that all words used "to?ti:k" (تعطيك/gives you) “toləbbi:" (تلبي/fulfills), and "mə2a:k" (معاك/accompanies you) are confined to humans. In fact, using such figures of speech has the ability to add more vivid attributes into services or things advertised. Lapšanská (2006) argues that the combination of a good sense of sight and hearing usually found in antithesis often triggers audiences' good emotions and urges their purchasing desire. In Image 11, the balance between "Pol?əwwəl" (الأول/first) and

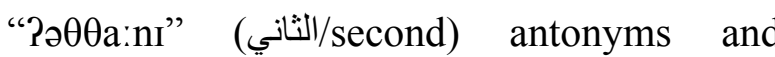
between "Xattak" (خطك)/your line) and "baladak" (بلدك/your home country) gives a harmonious sound. They all belong to the same part of speech and each pair rhymes with the same number of syllables. As for "kulləna" (كلن/all - see Image 4) and "wa:hid" (واحد/one - see Image 4) the antonym is clear here between singular and plural and they are also harmonious with the nouns they determine in the same ad, i.e. "niqa:tana" (نقاطنا/our credits - see Image 4) and "alze:b" (الجيب/the pocket - see Image 4). It is worth noting here that apparently these telecom companies are partial to using the latter semantic aspects more than other known ones such as metonymy, polysemy, homonymy, or simile.

\section{ii. The syntactic level}

The employment of syntactic aspects within the text is evident in the data. They are concerned with the structure of the text and the distribution of the grammatical relations within a given utterance. Lapšanská (2006) reports the use of two major syntactic aspects in ads: sentence type and structure. Regarding the first, it is associated with different types of discourse functions such as statements, questions, directives and exclamations. Sentence structure on the other hand, refers to the structural tendencies used by advertisers such as schematic patterning, ellipses, and incomplete sentences. Regarding sentence types, it would appear from the data that the "imperative" is the most commonly used sentence type found in many of the ads. The following examples illustrate this clearly: The verbs “Jərrrbha” (جربها/try - see Image 12), 
“oћşชl” (احتل/get - see Image 13), "IstəmtıY" (استمتع/enjoy - see Image 13), and "ћəmmil" (حمّل/download - see Image 14) are all imperatives. The excessive use of these imperative verbs coincides with what Giordano (2000) reports; a high usage of imperative clauses is evident in direct advertising. It would appear that these imperatives are used to evoke some type of action by the audience; making the message a one-to-one type of conversation. This finding is very similar to what was reported by Leech (1972; as cited in Lapšanská, 2006). These types of ads, which use the imperative, can be considered, as Bly (1990) suggests, a command ad because it commands the consumer to take action (Giordano, 2000). It is worth pointing out that 'interrogatives' were also identified in the data. Lapšanská (2006) states that they are used by copywriters to elicit a sense of personal communication with consumers. A good example of this is evident in one of the Zain ads (Image 15) "lilhi:n tidfə९" (للحين تدفع/Still paying?) which uses the interrogative to apparently get closer to consumers by helping them interact with the ad through the idea of answering the question in their minds.

In addition to evidence of sentence types in the data, there were also instances of the use of different sentence structures. Parallelism is one such structure; a form of schematic pattering that can be defined as "repetition of formal patterns" (Leech 1972, pp. 186; as cited in Lapšanská, 2006). An example of this is clear in Mobilys' ad (Image 4) where the first part of the text "niqa:tana kollana wəlze:b wa:hid” (نقاطنا كلنا و الجيب واحد / all our credits in one pocket) exactly has the same structure as the second part "niqa:t

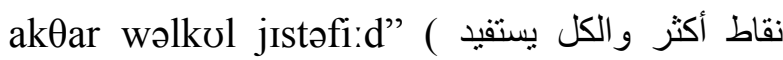
/more credits benefit all). Similarly, Zain utilizes the same technique in Image 11 by using equal number of constituents with equal structure in both clauses " $\chi$ ottək alawwal" (خطل الأول/your first line) and "baladak aөөa:ni” (بلدك الثاني/your second home). According to Lapšanská (2006), this rhetorical tool accelerates the sensational tone of the message and its importance. Another good example of sentence structure evident in the data is Ellipses. The HALA package ad for Zain (see Image 15) presents one type of ellipsis, and that is "situational ellipsis" of the interrogative clause. The omitted part of the question is understood from the context and from the background knowledge of the reader as "for all these services?" which include services such as calls, text messages, and Internet, as shown in the image which are given for free if one subscribes to the "HALA" package. This finding is very similar to what was identified by Greenbaum and Quirk (1990, as cited in Giordano, 2000). In most instances, the consumer will most probably understand the point, without seeing the word "fa:tu:ra" (فاتورة/bill). This form of ellipsis is used to presuppose a solution to 
potential consumers (Myers, 1994; as cited in Giordano, 2000); asking them to subscribe to HALA instead of paying for different services that HALA has. Using ellipsis in advertising has so many advantages: it can save money and space (Goddard, 1998); it is used to avoid directing consumers' attention to aspects of the text which do not serve a company's interest (Cook, 1996); and it creates a feeling of informality since their main use is in conversational contexts.

Another sentence structure that was used in the data was the "incomplete sentence". In Image 16, the STC ad represents a good example of this where there is an absence of a linking verb: "Pəl२əzhıza Pəððaki:ja mə3зa:nən məऽə ba:qa:t Pəlmufəwtər Pəlzədi:da “ الأجزة الذكية مجاناً مع باقات المفوتر الجديدة/free smartphone devices with the new Postpaid plans". It could be written as "Poћşul Gəla PəlPəzhıza Pəððaki.ja" “ احصل Get free smartphones...” or "PəlPəzhıza Pəððaki:ja motawaffıra mə33a:nən məSa” “ "الأجهزة الذكية منوفرة مجاناً مع .../Smartphones are freely available with...". Yet, there is no need to mention the verb since the accompanying image answers all the potential questions consumers might ask about the brands of smartphones they would get if they subscribe to "HALA". Apparently, STC does not need to explicitly state the subscription conditions since it does not serve the ad's purpose. Mobily also uses ellipsis (see Image 17); the text does not tell the consumer what it is that makes "Al-Hilal" club fans get special tariffs for their calls if they "subscribe" to The-Blue Wave pack. A tactic used by both companies to draw their consumer's attention to their product.

\section{iii. The morphological and lexical level}

This section will focus on the most common morphological aspects found in ads and the typical lexical choices favored by copywriters. With regards to the most commonly used morphological features, a very clear example found in many of the ads is the utilization of "personal pronouns". According to Giordano (2000), they make any message more personal. The most common pronoun evident in the data is the second person "you" and its possessive form "your". Interestingly, most of the data had instances of this second person masculine pronoun regardless of the gender of the desired addressee, unless they were specifically addressing female consumers. According to Al-Azzam (2014), such intentional use of the language is used to "create certain effects or achieve a linguistic power on the audience". From another perspective, Lapšanská (2006) claims that using this specific pronoun has the ability to bring the ad and the consumer closer. A good example of this is clear in the Zain ad when it used "nəssıq haja:tək" ( نسّقق حياتك /Sort your life - see Image 18). According to Ogilvy (1983), advertisers tend 
to use "you/your" because of the assumption that consumers are usually alone while reading an ad; so, it indicates a close relationship with the readers. On a similar note, this use was also evident in the Mobily ads: "bitaqatək nafiðətək" (بطاقتك نافذتك)/your card, your window- Image 19). The utilization of the second person masculine pronoun, again, is clear in STC ads as is evident in Image 10 "Pəfla:mak wə moselsela:tak" (أفلامك و مسلسلاتك)/your movies \& series). According to Hofstede, gender is one of the layers culture might be reflected through and in which it differentiates people belonging to the same culture (as cited in Panigrihi \& Chandra, 2010). Such expressions of gender, Panigrihi and Chandra (2010) state, can influence the building of advertisement and its effect and can have a deep communicative impact. They add, copywriters even take care of the various cultural levels as whether the society is individualist or collectivist or whether it is feminist or masculine. In the current data, this is clear in the invasive use of the masculine pronoun which might imply a good understanding of the language system put in place.

The data also had instances of lexical aspects. One such example is what SamaruCharles (2002, p. 1) names 'rule-breaking techniques' (i.e. misassignment of semantic roles). All three ads in Images 10, 18, and 19 clearly illustrate this. They specifically give the agent role to things that cannot be agentive. The choice of words such as "musəlsəla:t wo Pəfla:m" ( مسلسلات (ن أفلام/movies \& series - see Image 10), "nəssiq" (نسق/sort - see Image 18), and "bitaqah" (بطاقة/card - see Image 19) are good examples of the misassignment of the agent role, where all of them cannot perform actions that usually pertain to humans. Specific emphasis on the words depicts the following: “mosəlsəla:t wə Pəfla:m" (مسلسلات و أفلام /

TVseries and movies - see Image 10) cannot accompany a person wherever he/she goes; nor can "həja:h" (حياة/Life - see Image 18) which is an abstract notion be placed in the role of patient that is to be arranged; and finally, nor can a word such as "bita:qah" (بطاقة/credit card - see Image 19) be opened like a window yet all were assigned agentroles.

Still another lexical aspect found in the data is the use of 'foreign words' borrowed from other languages (English in the case of this study's dataset) either in names of services or products. According to Graddol (2004, p. 1329), the "world's language system is undergoing rapid change because of demographic trends, new technology, and international communication. These changes will affect both written and spoken communication" and this is apparent from the dataset. Mobily, for instance, uses the word 'application' (Pablıke:Jin- Image 14) in Arabic transcript instead of using the Arabic counterpart "totbi:q" (تطبيق/application). 
Similarly, Zain uses the word 'chat' written in Arabic rather than its translated correspondent “dərdəJa" (دردشه/chat- Image 20). As for STC, it also exploits foreign/borrowed words; its use of the word 'upload' (Pablo:d - Image 6) service which could be replaced by the Arabic word "təћmi:l" (تحميل/upload). Khrist and Mohammad (2014) report that there are many reasons why people borrow words from other languages and one of them is when people look up at a language as having a high status which most probably explains the situation happening in Saudi Arabia and other countries from around the world. Sometimes borrowed words are even incorporated into an ad close to an adjacent Arabic word such as "ffa:t Jəћna:t" (شحنات تثنات/chat and recharge see Image 20). Interestingly, the latter example illustrates the essence of Arabization, a process of localizing a foreign text and then reshaping it to match a word that comes close to Arabic pronunciation and sound (Al-Qahtani, 2000). It would appear that the aforementioned techniques used in these telecom ads are interesting ways to attract consumers due to the different ways they use words.

\section{iv. The phonological level}

This phonological level includes a number of mnemonic devices. They can include the following: rhyme, rhythm, alliteration, and assonance, all of which have a memorial effect attached to them as their uniqueness lies in their ability to stay in the memories of consumers for the sound harmony they convey (Lapšanská, 2006). Rhyming sounds for example have the power to be conducive to memory and therefore memorable and this is evident in the data: "hrla:l xәja:lı" ( هلالي خيالي/Al-Hilal club is where I want to be - see Image 17) and "ju:d and məwłu:d" (جود /Available -Jud - see Image 21) are all good illustrations of word pairs that end in the same sound. The data also reveals examples of rhythm. According to Leech (1972, cited in Lapšanská, 2006), this type of mnemonic device consists of patterns composed of rhythm groups of similar or identical stressed and unstressed syllable. The Zain ad (Image 20) not only represents rhyme, it also exhibits an iambic meter; an unstressed syllable followed by a stressed one. The following example illustrates this clearly: "liahməd

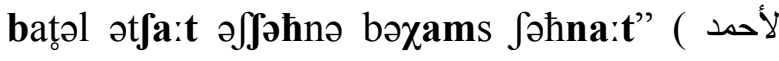
/ For Ahmed, the hero of chat, each recharge adds 5 credits) where the bold characters indicate the stressed syllables. In fact, the same ad also represents a form of alliteration; a successive sequence of the same consonant sounds as was evident in the sound / $/$ / which was repeated three times throughout the text. As for assonance, it is similar to alliteration with the only difference is that it focuses on vowels rather than consonants (Lapšanská, 2006). The Mobily ad (Image 17) exhibits assonance in the recursive occurrence of the long vowel 
/a:/; twice in the words "hila:lı" and once in " $\chi$ aja:li" as well as the vowel/I/ which is repeated several times in the text. It is clear from all of the examples in all the linguistic levels that have been discussed that these three companies are very creative with their use of language.

\section{Conclusion and Implications}

The aim of the current study is to investigate the most prominent linguistic features in the OBAs of three well-known telecom companies in Saudi Arabia: Zain, Mobily, and STC. The data analysis shows that all three companies basically use very similar semantic, syntactic, lexical, morphological, and phonological techniques in their ads. The study also provides evidence that the products and services that these telecom companies advertise indicate a deep understanding of the Saudi culture and its people. Finally, the findings will provide Saudi-based telecom companies with empirical data that could help their language marketing tactics. Following up this study, it would be interesting to investigate the social and cultural aspects that underlie the construction of advertising in different languages and cultures. Moreover, it would be of great value, from a sociocultural perspective, to research and compare the OBAs of the different countries where some of these companies operate (e.g. the Zain telecom company). Furthermore, using surveys and focus groups to identify what consumers believe are the most significant characteristics of online banner ads would provide great insights to the field. More research needs to be done in this region of the world to gain a better understanding of the advertising field.

\section{$\underline{\text { References }}$}

Advertising (n.d.). In the American Heritage Online Dictionary. Retrieved May 22, 2014, from: http://ahdictionary.com

Ahmed, M. (2011). The effect of e-commerce on electronic banking services. Al-Masrifi Journal, 1(60): 10-28. Retrieved from: http://sdl.opac.mandumah.com

Al-Azzam, B. \& Al-Quran, M. (2014). Inflectional Deviation of Gender in the Qur'an. Studies in Literature and Language, 8(2): 16-25.

Retrieved from http://www.cscanada.net/index.php/sll/article/ view/4452

Albers-Miller, N. \& Gelb, B. (1996). Busines advertising appeals as a mirror of cultura dimensions: A study of eleven countries. Journal of Advertising, 25(4) (Winter, 1996) pp. 57-70. Retrieved from: http://www.jstor.org

Al-Huqail, A. (2012). History of creative advertising affecting purchase decisions of Saudi women. King Saud University Journal, 24(2), 439472. Retrieved from Al-Manthomah database: http://sdl.opac.mandumah.com

Alijani, G., Mancuso, L., Kwun, O., \& Omar, A (2010). Effectiveness of online advertisement factors in recalling a product. Academy of Marketing Studies Journal, 14(1), 1-10.

Al-Qahtani, D. (2008). Trends in Saudi society towards tourism advertising on Arabic satellite channels: A qualitative study. Arabic Journal of Media and Communication, 3(3), 286-304. Retrieved from: http://sdl.opac.mandumah.com 
Al-Qahtani, S. H. (2000). Arabization in written discourse in Saudi Arabia (Phd Dissertation). Ball State University, Muncie, Indiana. Retrieved from: http://search.proquest.com

Al-Sayyed, A. (2012). Using event study to evaluate the effect of business returns advertising: A case of Egyptian banks. The Scientific Journa of Business and Commerce, (n.v)(3), 623-640. Retrieved from:

http://sdl.opac.mandumah.com

Barhouma, I. (2005). Language and advertisement communication: A case of the spread of western names in billboards in Jordon. Journal of the Arabic Language Academy in Jordon, (n.v)(69), 65-91. Retrieved from: http://www.majma.org.jo

Cheng, H. (2014). The handbook of international advertising. West Sussex: Wiley.

Donaldson, D. (2008). Online advertising history. London: Bournemouth Media School.

Evans, D. (2009). The online advertising industry: Economics, evolution, and privacy. The Journal of Economic Perspectives, 23(3), 37 60. Retrieved from: http://www.jstor.org/stable/27740539

Glaser, B. G., \& A. Strauss (1967). The discovery of grounded theory: Strategies for qualitative research. New York: Aldine.

Giordano, M. (2000). Linguistic aspects of English and Spanish print advertising (Master Thesis) California State University, Long Beach, California. Retrieved from: http://search.proquest.com

Graddol, D. (2004). The future of language. Science, 303: 1329-31. Retrieved from

http://media.proquest.com

Gully, A. (1996-97). The discourse of Arabic advertising: preliminary investigation. Journal of Arabic and Islamic studies, 1, 1-49. Retrieved from: http://www.lancaster.ac.uk
Internet Advertising Revenue. (2014). IAB Internet advertising revenue report 2013: Full year results. Retrieved from: http://www.iab.net

Ishida, R. (2006). IPA Character Picker 11. Retrieved Apr. 6, 2015, from http://people.w3.org/rishida/scripts/pickers/ipa I

Janoschka, A. (2004). Web advertising: New forms of communication on the Internet. The Netherlands: John Benjamins B.V.

Kassarjian, H. H. (1977). Content analysis in consumer research. Journal of Consumer Research 4: 8-

Khrisat, A. A. \& Mohammad, M. S. (2014) Language's borrowings: The role of the borrowed and Arabized words in enriching Arabic language. American Journal of Humanities and Social Sciences. 2(2): 133 142. Retrieved from http://www.wscholars.com

Kover, A. J. (2001). Editorial: Content Analysis and bridges. Journal of Advertising Research, 41(2): 5.

Kutubkhaneh, I., Baghdadi, A., Ghanem, A., AlJammal, R. \& Andergiri, M. (1993). TV advertising and values of Saudi society: A case study of Jeddah inhabitants. King Abdulaziz University Journal, 3(n.i), 3-67. Retrieved from:

http://sdl.opac.mandumah.com

Lapšanská, J. (2006). The language of advertising with the concentration on the linguistic means and the analysis of advertising slogans (Diploma Thesis). University of Komenského,

Bratislavě. Retrieved from: http://diplomovka.sme.sk/zdroj/3091.pdf

Liles, S. (2009). Online advertising: What kind of impact do embedded ads have on an Internet user's perception of an advertisement when it is incongruous with the story content? (Master Thesis). University of South Alabama, Alabama. Retrieved from: http://books.google.com.sa 
Panigrihi, D \& Chandra, N. (2010). Advertisement: Cultural transfusion, refraction and evolution. Journal of Literature, Culture and Media Studies, 2(3), 86-101. Retrieved from: http://www.inflibnet.ac.in

Petley, J. (2003). Advertising. London: Hodder Wayland.

Ryan, G., \& Bernard, H. R. (2003). Techniques to identify themes. Field Methods, 15(1), 85109

Samaru-Charles, L. (2002). Rule-breaking in the language of advertising. (BA Thesis) Swarthmore College, Swarthmore.
Schrank, J. (1993). The language of advertising claims In T. K. Anderson and K. Forrester (Eds.), Point counterpoint: Eight cases for composition ( $2^{\text {nd }}$ ed.) (pp. 184-188). Fort Worth: Harcourt Brace Jovanovich.

Strauss, A., \& J. Corbin (1990). Basics of qualitative research: Grounded theory procedures

and techniques. Thousand Oaks, CA: Sage.

Unwin, S. (1974). How culture affects advertising expression and communication style. Journal of Advertising, 3(2), 24-27. Retrieved from: http://www.jstor.org

\section{Appendix 1}






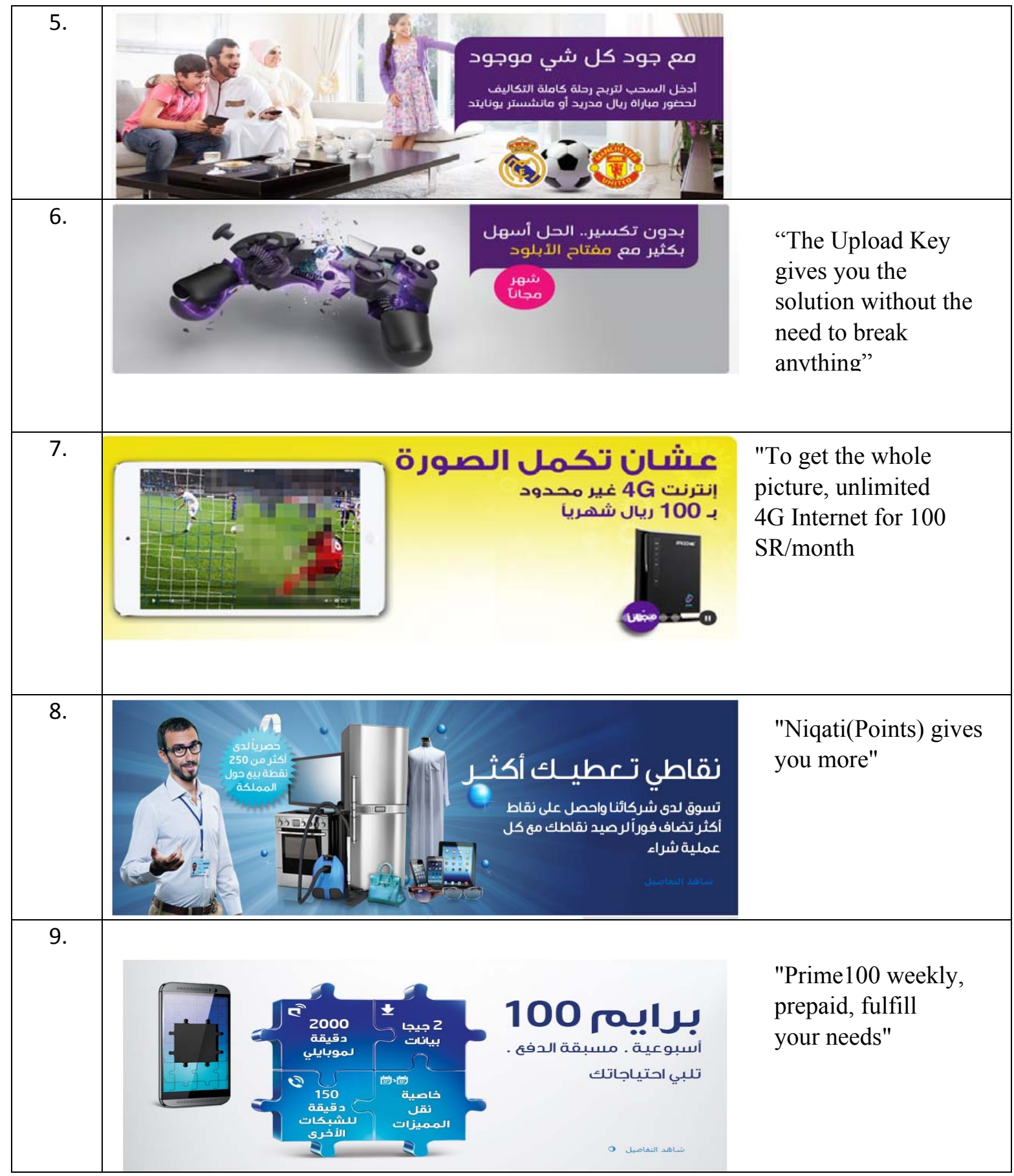




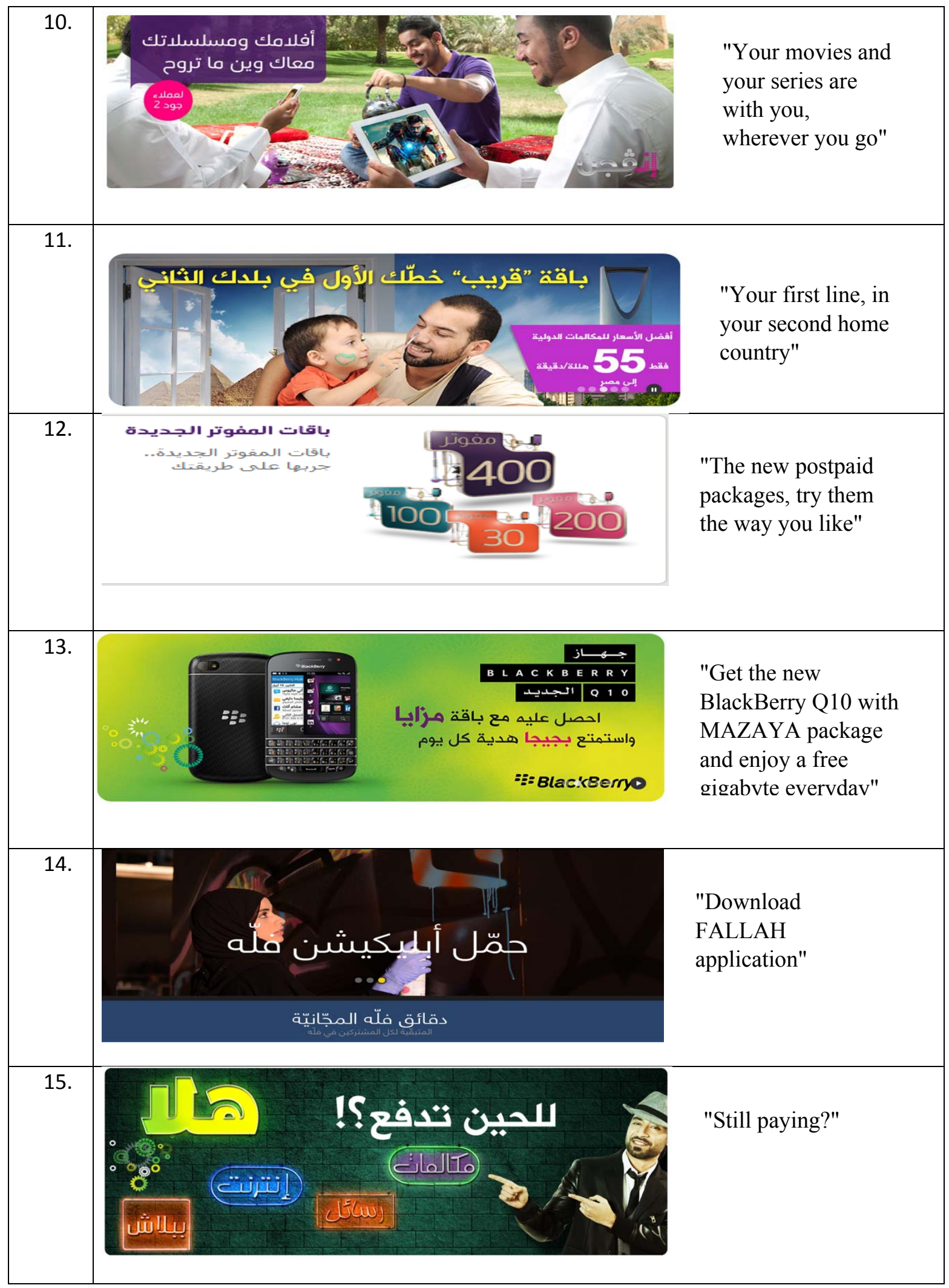




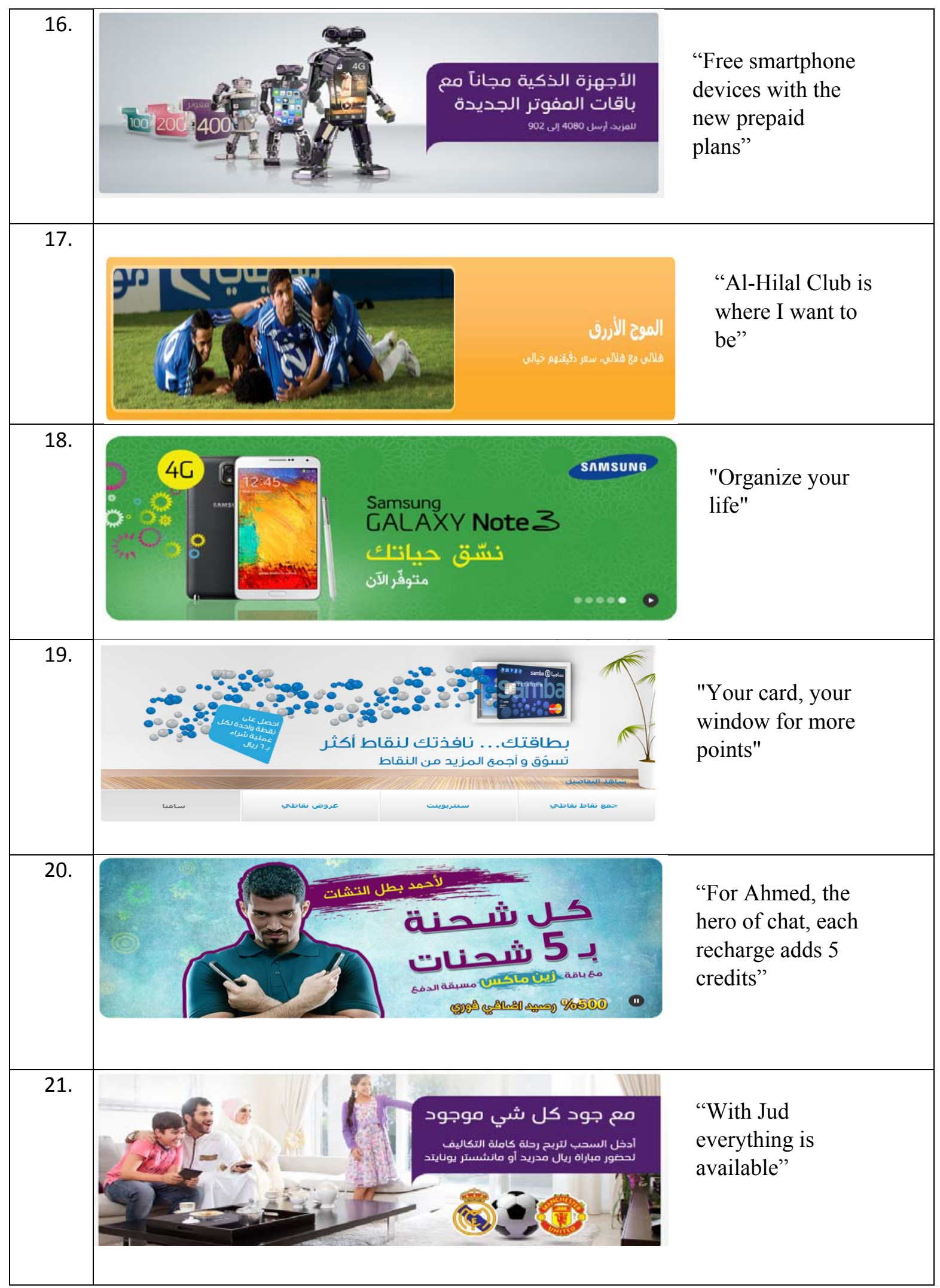






